\section{Rückführungskette, metrologische}

C. Vidal ${ }^{1}$ und W.-R. Külpmann ${ }^{2}$

${ }^{1}$ Landeskriminalamt Niedersachsen, Dezernat 53 „Chemie“, Hannover, Deutschland

${ }^{2}$ Hannover, Deutschland

Synonym(e) Messtechnische Rückführungskette

Englischer Begriff metrological traceability chain; traceability chain
Definition Folge von Normalen (s. - Normal) und Kalibrierungen (s. $>$ Kalibrierung), die verwendet wird, um ein $\checkmark$ Messergebnis auf eine Referenz zu beziehen.

\section{Literatur}

Brinkmann B (2012) Internationales Wörterbuch der Metrologie (VIM) Deutsch-englische Fassung. ISO/IEC-Leitfaden 99:2007, 4. Aufl. Beuth-Verlag, Berlin 